\title{
25 Research Square \\ Possible protective effects of trans-resveratrol against 1,4-dioxane induced toxicity in meristematic cells of plant bioassays
}

Deniz Kurt

Giresun Universty

Emine Yalçın ( $\nabla$ emine.yalcin@giresun.edu.tr)

GRU https://orcid.org/0000-0002-5280-5375

Kültiğin Çavuşoğlu

Giresun University

Research article

Keywords: 1,4-dioxane, Allium test, Chromosomal aberrations, Micronucleus, Oxidative stress, Transresveratrole

Posted Date: April 14th, 2020

DOl: https://doi.org/10.21203/rs.3.rs-20747/v1

License: (c) (i) This work is licensed under a Creative Commons Attribution 4.0 International License. Read Full License 


\section{Abstract}

Background In this study, the protective effects of trans-resveratrol against 1,4-dioxane induced toxicity in meristematic cells were investigated. For this purpose, Allium test which is a reliable test was used and the alterations in all experimental groups were examined by using physiological, cytogenetic, biochemical and anatomical parameters.

Results As a result of the analysis, it has been determined that 1,4-dioxane causes serious abnormalities in Allium cepa meristematic cells. It was determined that in 1,4-dioxane treated group germination percentage regressed 1.6-times, root length reduced 12.7-times and weight gain decreased 7.7-times compared to control group. It has been observed that trans-resveratrol administration with 1,4-dioxane causes improvement in physiological parameters and reduces the damage rate from 0.4 to 0.16 . Mitotic index, micronucleus and chromosomal abnormality frequency were investigated as cytogenetic parameters. It was determined that mitotic index decreased, chromosomal abnormalities and micronucleus frequency increased in 1,4-dioxane treated group. Trans-resveratrol treatment was found to cause a dose dependent improvement in genotoxic effects induced by 1,4-dioxane. Changes in the antioxidant system in all experimental groups were determined by measuring malondialdehyde, glutathione, superoxide dismutase and catalase enzyme levels. It was determined that 1,4-dioxane administration caused an increase in malondialdehyde level, decreased glutathion rate and induced antioxidant enzyme activity. Trans-resveratrol application was found to cause improvement in these alterations induced by 1,4-dioxane. It was observed that the $200 \mathrm{mg} / \mathrm{mL}$ trans-resveratrol+1,4-dioxane treatment caused a 1.9-fold decrease in malondialdehyde level which is indicator of lipid peroxidation compared to only 1,4-dioxane treated group. The abnormalities caused by 1,4-dioxane application in the meristematic cells are also found in the anatomical structure. In 1,4-dioxane treatment group, anatomical changes such as cell deformation and cortex wall thickening were observed. The frequency of these changes decreased with trans-resveratrol administration.

Conclusions As a result, it was determined that 1,4-dioxane caused a versatile toxicity in Allium cepa meristematic cells, while trans-resveratrol was found to have a dose-dependent protective feature against 1,4-dioxane-induced toxicity.

\section{Background}

With the increasing industrialization, the use of chemicals has increased in various sectors and the use of many additives to improve the properties of industrial products has become widespread. 1,4-dioxane, which is used to fix solvents with its hydrophilic and anti-chlorination properties, is frequently used in personal care and cleaning products, varnishes, paints and disinfectants. 1,4-dioxane which is also present in the structure of adhesives and inks, is also used in the manufacture of insecticides, herbicides and softeners [1]. Due to its frequent use in many products, contamination to the environment and people has also become inevitable. Especially in agricultural areas, direct use as an insecticide or as a component of pesticides leads to serious contamination. As a result of its use as an insecticide, it 
accumulates in agricultural areas, pollutes water environments and shows toxic effects on non-target organisms such as plants. In particular, accumulation in plants causes 1,4-dioxane to be transmitted to other living organisms and humans through the food chain. 1,4-dioxane has been reported to cause damage to the liver and kidneys as exposure time and dose increase and is included in the list of carcinogenic substances [2,3]. However, in the literature, both negative and positive results were obtained in terms of genotoxic effect in 1,4-dioxane-related studies. Roy et al. [4] reported that there was no genotoxic effect of 1,4-dioxane, while the Morita and Hayashi [5] stated that 1,4-dioxane is mutagenic in Ames test. In this study, 1,4-dioxane toxicity was investigated with different parameters and a contribution has provided to the solution of the complexity of 1,4-dioxane toxicity in the literature. It was also tested whether trans-resveratrol (t-resv) could neutralize 1,4-dioxane toxicity. Powerful antioxidant compounds can be used to reduce or neutralize the harmful effects of toxic substances that we are exposed to in daily life through diet or different contamination. However, considering the diversity in plant specis and herbal products, such studies are inadequate. In this study, protective properties of t-resv against 1,4-dioxane toxicity were investigated with multiple parameters.

Resveratrol (3,4',5-trihydroxy-trans-stilbene) is an phytoalexin commonly found in consumable foods such as grape, peanuts and red wine [6]. Resveratrol is known to have properties such as lipid peroxidation inhibitory, copper chelating, radical scavenging, anti-inflammatory activity and anticarcinogenic activity [7]. Resveratrol has been reported to be protective against many diseases such as arteriosclerosis and cancer in the literature and this feature has been explained by many mechanisms. Activating the antioxidant system, facilitating antioxidant mechanisms, suppressing the formation of superoxide radical and $\mathrm{H}_{2} \mathrm{O}_{2}$, inhibiting lipid peroxidation induced by reactive oxygen are some of these mechanisms [8,9]. These mechanisms may be in the form of a specific protection against direct toxic effect or indirect protection by activating other mechanisms. Resveratrol has two geometric isoforms, cisresveratrol and trans-resveratrol. And the main form, the trans isomer concentration, contributes significantly to its biological activity [7]. Resveratrol is a polyphenol with antioxidant properties, while tresv is a polyphenolic phytoalexin with anti-inflammatory, antioxidant and anticancer properties. The trans-resveratrol has a planar backbone, while the resveratrol comprises two main planes. Due to its structural properties, t-resv is a form associated with a potential protective property. The protective properties of t-resv have been demonstrated by various studies in the literature. T-resv is reported to inhibit metal-induced lipid peroxidation and to reduce lipid peroxidation caused by ethanol $[10,11]$. In addition, it has been reported that due to its antioxidant properties, it has a cardioprotective effect against ischemia [12]. In the literature, the protective properties of cis-resveratrol or trans-resveratrol against various agents have been investigated, but no protective properties of t-resv against 1,4-dioxane toxicity have been investigated. In this study, the dose-dependent protective properties of t-resv against biochemical, genetic, physiological and anatomical toxicity induced by 1,4-dioxane were investigated.

\section{Results}

\section{Germination Parameters}


In this study, the toxic effects of 1,4-dioxane and the amerolative effects of t-resv against this toxicity have been investigated in Allium cepa which is used as a model organism in toxicity tests. Firstly, effects on germination and germination related parameters were examined and the results were given in Table 1. No abnormalities were detected in the germination parameters of Group I, Group II and Group III, while similar germination rate, root length and weight gain levels were found between the groups. Root length, germination rate and weight gain decreased by $12.6,1.6$ and 7.7 times, respectively in $100 \mathrm{mg} / \mathrm{L} 1,4-$ dioxane treated group compared to control group. T-resv treatment with 1,4-dioxane in Group V and Group VI showed an improvement in germination parameters, but the levels were far behind the control group. In Group VI where $200 \mathrm{mg} / \mathrm{L}$ t-resv and 1,4-dioxane were applied together, germination rate was 1.4 times higher than in 1,4-dioxane treated group and 1.19 times lower than in control group. When the relative injury rates were examined, the highest injury was observed in Group IV as 0.40 , whereas it was found to decrease with the application of $100 \mathrm{mg} / \mathrm{L}$ and $200 \mathrm{mg} / \mathrm{L} \mathrm{t}$-resv. In summary, 1,4-dioxane inhibited all parameters related to germination in the model organism and caused significant relative injury rate. However, it was determined that t-resv treatment regressed the negative effects of 1,4-dioxane and caused significant improvements. It was observed that these improvements increased as t-resv dose increased and more dominant at $200 \mathrm{mg} / \mathrm{L}$.

\section{Antioxidant-oxidant balance}

1,4-dioxane induced changes in Glutathion (GSH) and malondialdehyde (MDA) levels, which are parameters related to oxidative stress, were given in Fig. 1. For both parameters, there was no significant difference between the control group, $100 \mathrm{mg} / \mathrm{L}$ and $200 \mathrm{mg} / \mathrm{L}$ t-resv treated groups $(p>0.05)$. The fact that MDA level was increased 5.09-fold in 1,4-dioxane treated group compared to control group indicates lipid peroxidation and oxidative stress formation in meristematic cells. It was determined that this oxidative damage induced by 1,4-dioxane regressed with t-resv application. In group V and VI, it was found that t-resv treatment with 1,4-dioxane caused an significantly improvement in MDA and GSH levels ( $p>0.05)$. This improvement was found to increase with increasing t-resv dose, but there was no direct proportional increase. The most significant protection against oxidative damage was observed at a dose of $200 \mathrm{mg} / \mathrm{mL}$ t-resv treatment. It was determined that MDA level decreased 1.93 fold and GSH level increased 1.85 fold in the $200 \mathrm{mg} / \mathrm{mL}$ t-resv+dioxane treated group compared to Group IV and these changes showed the protective role of t-resv against oxidative stress.

Oxidative stress in cells is removed by enzymatic antioxidant system. Superoxide dismutase (SOD) and catalase (CAT) are two important enzymes for the removal of radical products, and no change in the activity of these enzymes was found in the control group and the groups treated with only t-resv (Fig. 2). It was found that 1,4-dioxane treatment caused changes in SOD and CAT activity in meristematic cells and enzyme activities increased 2.1 and 2.6 times, respectively, compared to control group. This increase is a response to oxidative damage evidenced by increased MDA and decreased GSH content by 1,4dioxane effect. The enhancing effect of 1,4-dioxane on SOD and CAT enzymes began to normalize with tresv application. As a result of t-resv application with 1,4-dioxane, SOD and CAT activities were observed to approach the control group levels, but the levels remained above the control group. Increased SOD 
activity in the group treated with 1,4-dioxane decreased $34.7 \%$ in the group receiving $200 \mathrm{mg} / \mathrm{mL}$ t-resv with 1,4-dioxane. CAT activity in the same group decreased by $47.4 \%$ compared to Group IV.

\section{Cytogenetic parameters}

The frequency of chromosomal abnormalities (CAs) induced by 1,4-dioxane in the meristematic cells were given in Table 2 and Fig. 3. Only a few unequal distribution of chromatine and vagrant chromosome were observed in Group I, II, and III, but these abnormalities were not statistically significant ( $p>0.05)$. In 1,4-dioxane treated group, chromosomal abnormalities such as fragment, sticky chromosome, unequal distribution of chromatine, bridge and vagrant chromosome were observed with a high level. While the highest fragment frequency was observed among CAs, vagrant chromosome formation was observed to be low compared to other CAs. It was determined that the t-resv application with 1,4-dioxane decreased the frequency of CAs formations. Briefly, t-resv exhibited dose-dependent protective properties, but this protective property was not directly proportional to the dose. In $200 \mathrm{mg} / \mathrm{L} \mathrm{t}$-resv+dioxane treated group, fragment frequency (the highest CAs type) observed in this study was found to be reduced by $40.0 \%$ compared to the 1,4-dioxane-treated group. Abnormalities observed in Group V and Group VI were still higher than in the control group, so t-resv reduced the toxic effect of 1,4-dioxane but could not completely neutralize it.

Micronucleus $(\mathrm{MN})$ frequency and mitotic index $(\mathrm{MI})$ ratios of all treatment groups were given in Fig 4. Very low MN formation was detected in the control group and the groups receiving only t-resv, and there was no significant difference between these groups ( $p>0.05)$. This result shows that $t$-resv does not cause the formation of MN at the doses tested. Similarly, a parallel level was obtained in MI ratios for all three groups and no difference was observed between Groups I, II and III. It was determined that MN ratio increased significantly and reached $49.00 \pm 3.39$ in 1,4-dioxane treated group. In Group IV, the MI rate was significantly redounded and the $\mathrm{MI}$ rate was reduced by $50.1 \%$ compared to the control group. The application of t-resv resulted in improvement in 1,4-dioxane induced $M N$ formation and abnormalities in MI. It was determined that $100 \mathrm{mg} / \mathrm{L}$ and $200 \mathrm{mg} / \mathrm{L}$ t-resv treatment in Group V and VI reduced MN formation by 1.58 and 2.13 times, respectively compared to only 1,4-dioxane treated group. T-resv showed similar amerolative effect in $\mathrm{MI}$ rates and the most significant improvement was achieved in Group IV treated with $200 \mathrm{mg} / \mathrm{L}$ t-resv. It was determined that $100 \mathrm{mg} / \mathrm{L}$ and $200 \mathrm{mg} / \mathrm{L} \mathrm{t}$-resv application with 1,4-dioxane increased $\mathrm{Ml}$ ratio by 1.50 and 1.79 times, respectively compared to only 1,4-dioxane treated group.

\section{Anatomical changes}

The anatomical changes caused by the application of 1,4-dioxane in A.cepa meristematic cells were shown in Fig 5. While no abnormality was observed in the anatomical structures of Group I, Group II and Group III, various anatomical changes were observed in the 1,4-dioxane treated group. These changes are flattened cell nuclei, cell wall thickening and cell deformation. In the root tissue where the nutrient uptake of the plant is provided, the epidermis cells are the place where the first contact with exogenous substances is provided. The fact that 1,4-dioxane application leads to deformation in epidermis cells 
confirms this hypothesis. It was found that the frequency of 1,4-dioxane induced anatomic abnormalities decreased with t-resv administration (Table 3). Anatomical improvements were more pronounced in Group VI treated with $200 \mathrm{mg} / \mathrm{mL}$ t-resv.

\section{Discussion}

In this study, it has been determined that 1,4-dioxane causes a versatile toxic effect in A.cepa meristemetic cells, which is a eukaryotic model organism, and t-resv reduces this toxicity. In 1,4-dioxane treated group significant reductions in radicle lenght, weight increase and germination rates were determined and high realtive injury rate was observed. Abnormalities observed in germination parameters may be related to toxic effects of 1,4-dioxane. Dioxane has direct or indirect toxic effects on living organisms. The direct effect occurs as a result of the reaction of 1,4-dioxane and molecular oxygen, which causes the production of free radicals and the formation of oxidative stress [13,14]. Oxidative stress in plants causes autocatalytic peroxidation of membrane lipids and pigments, modification of membrane permeability and consequently damage to cell structure [15]. In particular, the rapidly dividing meristem cells are more affected by oxidative stress, and root growth is inhibited and this inhibition is reflected in germination and weight gain. Similarly, it has been reported in the literature that application of 1,4-dioxane causes inhibition in weight gain, germination rate and root growth of test organisms [1,16]. Tresv showed an amerolative effect against 1,4-dioxane induced damage in germination parameters. Resveratrol is present in cis and trans isomeric form, and the concentration of the trans isomer, the main form, significantly contributes to biological activity [7]. In the literature, resveratrol is reported to be a potent antioxidant component that has been proven in various in vitro and in vivo studies.

Chanbitayapongs et al. [11] reported that resveratrol inhibited metal-derived lipid peroxidation and showed antioxidant properties in in-vitro studies. Sun et al. [10] reported that resveratrol reduced lipid peroxidation induced by iron and ethanol. Since there is no data on the protective properties of t-resv against 1,4-dioxane toxicity in plants, this study is the first data on this subject.

MDA, GSH, SOD and CAT analyzes were performed to determine the effects of diosane and resve applications on antioxidant and oxidan balance. It was determined that dioxane application increased MDA level, decreased GSH level and induced antioxidant enzyme activities. It was found that these changes observed in antioxidant-oxidant balance started to normalize with resveratrol application. It is known that 1,4-dioxane causes free radical production and oxidative stress in living systems. Free radicals in the cells attack the unsaturated lipids containing carbon-carbon double bonds, causing lipid peroxidation. Low levels of MDA have been reported to act as regulators of gene expression in cells. However, high levels of MDA can easily interact with functional groups of molecules such as proteins, lipoproteins, DNA and RNA in the cell, causing adduct formation and different pathological conditions [17]. MDA is highly toxic and its toxicity is associated with Michael's ability to form adducts with thiol groups, facilitate protein cross-linking and induce mutagenesis [18]. Along with the increase in MDA, changes in glutathione levels were observed in meristematic cells treated with 1,4-dioxane. It was determined that glutathione level which is an antioxidant with tripeptide structure decreased 2.38 times in 1,4-dioxane treated group compared to control group. Briefly, the increase in MDA level and the decrease 
in GSH level in the same cells treated with 1,4-dioxane are indicative of obvious oxidative damage. Glutathions have been reported to be found in almost all cell parts of plant tissues such as cytosol, endoplasmic reticulum, vacuole, mitochondria, chloroplast, peroxisome. Reduced glutathione reacts with lipid peroxides and oxidizes during detoxification of these molecules and the level of reduced glutathione decreases [19]. In cells, the decreased glutathione level leads to reduced antioxidant capacity and the increased MDA level causes an enhanced oxidation. The decrease in GSH level and the increase in MDA level indicate the deterioration of antioxidant-oxidant balance. It was observed that this disrupted balance induced by 1,4-dioxane, started to improve with t-resv application. Resveratrol has scavenging activity on reactive oxygen species and shows significant effects on the radical induced cellular response [20]. Similarly, Al-Hussaini and Kilarkaje [21] reported that lipid peroxidation and macromolecule oxidation in the cell decreased with t-resv administration. In another study, Mikstacka et al. [22] reported that t-resv administration was effective in recovering significantly depleted GSH content in tested cells. Gupta et al. [23] reported that in oxidative stress-induced subjects the administration of 20 and $40 \mathrm{mg} / \mathrm{kg}$ t-resv administration resulted in a reduction in MDA levels, but no effect on GSH levels.

It has also been determined that 1,4-dioxane application induces SOD and CAT activities in A. cepa meristematic cells. SOD and CAT are involved in the removal of radical products in the cell. SOD catalyzes the dismutation of the highly reactive superoxide anion to $\mathrm{O}_{2}$ and the less reactive product $\mathrm{H}_{2} \mathrm{O}_{2}$ and the peroxide which is formed as a result of this reaction is destroyed by CAT enzyme [24]. Although there are studies showing that 1,4-dioxane causes oxidative damage and increases MDA level [25], there is no direct study investigating its effect on SOD and CAT activity. However, there are many studies in the literature that report changes in SOD and CAT activity in the presence of oxidative stress. Malar et al. [26] observed that in the presence of induced lipid peroxidation and oxidative stress SOD activity increased by $251 \%$ and CAT activity increased by $60 \%$ in Eichhornia crassipes leaf tissues compared to control. Macczak et al. [27] reported a reduction in GSH levels and alterations in SOD and CAT activities in the presence of oxidative stress caused by various chemicals inducing the formation of reactive oxygen species. In this study, t-resv treatment with dioxane ameliorated the enhanced SOD and CAT activity induced by 1,4-dioxane. These improvements can be explained by the role of t-resv in reducing oxidative stress and regulating enzyme induction. Similarly, Sadi et al. [28] specified that SOD activity increased in the presence of induced oxidative stress and decreased again after t-resv treatment, briefly they reported that t-resv treatment caused an improvement in the level of oxidative biomarkers. Pintea et al. [29] reported that t-resv directly contributes to antioxidant defense by scavenging reactive oxygen species and causing changes in superoxide dismutase, catalase and glutathione peroxidase activities.

1,4-dioxane, which causes oxidative stress in A. cepa meristematic cells, has also been found to cause chromosomal abnormalities such as fragment, sticky chromosome, unequal distribution of chromatine, bridge and vagrant chromosome. These genotoxic effects indicate that 1,4-dioxane disrupts genome stability, and these effects may be associated with 1,4-dioxane-induced oxidative damage. 1,4-dioxane leads to free radical formation, oxidative stress and lipid peroxidation in living systems $[13,14]$. The 
effects of oxidative stress on DNA have been investigated in detail and have been demonstrated by many studies in literature. Oxidative stress and free radicals cause DNA adducts, phosphodiester bond cleavages, chain breaks and mutations in bases [30]. Abnormalities in bases caused by 1,4-dioxane exposure cause A:T-T:A transversions and this mutation results from adenosine adducts [31,32]. All these changes in the DNA structure induced by 1,4-dioxane cause genome instability and the formation CAs. Similarly, Sağır et al. [16] reported that the application of 1,4-dioxane resulted in high CAs formations such as fragment, ascentric and dicentric chromosomes. In this study, it was also determined that genotoxic effects induced by 1,4-dioxane were decreased with t-resv treatment. Oxidative stress caused by 1,4-dioxane in organisms has been proved by the increased MDA levels in $A$. cepa root cells. Oxidative stress in cells also affects DNA and causes the formation of DNA base oxidation products. Agents that increase oxidative DNA damage increase cancer development. Inhibiting the formation of oxidative stress, which is the starting point of these abnormalities, will also inhibit mutation and cancer development. It has been shown in many studies that consumption of antioxidant-containing plants in daily diet reduces oxidative DNA damage levels and the incidence of human cancers [33]. Resveratrol increases the expression of glutathione peroxidase and catalase enzymes and induces scavenging of $\mathrm{H}_{2} \mathrm{O}_{2}$, thereby providing resistance to oxidative damage [34]. Agents such as resveratrol that reduce oxidative stress and consequently DNA damage have antimutagenic and anti-cancer effect. Jang et al. [35] reported that resveratrol has an anticarcinogenic effect and this effect is associated with inhibition of the initiation and promotion of carcinogenesis. Al-Hussaini and Kilarkaje [21] reported that DNA oxidation in the cell decreased in subjects treated with t-resv. Ungvari et al. [34] showed that DNA damage induced by oxidative stressor was reduced by $10^{-6}-10^{-4} \mathrm{~mol} / \mathrm{L}$ resveratrol application in a cell culture.

The cytogenetic effects of 1,4-dioxane and t-resv applications in meristematic cells were also supported by $\mathrm{MN}$ and $\mathrm{Ml}$ analysis. It has been proven by the increase in the frequency of $\mathrm{MN}$ and the decrease in $\mathrm{MI}$ rate that 1,4-dioxane causes genomic instability. The decrease in the MI ratio of 1,4-dioxane treated group can be explained by the oxidative stress created in the meristematic cell. Chemicals that trigger the formation of oxidative damage and cause glutathione reduction are reported to delay cell cycle by causing delayed progression through $\mathrm{G} 1$ and $\mathrm{S}$ phases and even stopping the cell cycle at the $\mathrm{G}_{2}$ point [36]. The fact that the 1,4-dioxane application causes an increase in MDA level, a decrease in gsh level and changes in antioxidant enzyme activities in meristematic cells is evidence of oxidative damage and this damage causes an inevitable delay in cell cycle. Similarly, Sağır et al. [16] reported that 1,4-dioxane administration caused a decrease in the Ml rate and reduced the number of dividing cells from $835 \pm 45.38$ to $438.5 \pm 23.31$. The decrease in MI ratio also explains the abnormalities caused by 1,4-dioxane in physiological parameters. Root growth, germination and weight gain are directly related to cell division, and the decrease in division rate negatively affects these parameters. DNA damage and MN formation also cause disruptions and abnormalities in the cell cycle. The formation of $\mathrm{MN}$ in a cell is an indicator of toxic effect and $\mathrm{MN}$ is caused by all chromosomes or chromosome fragments that do not belong to the main nucleus. $\mathrm{MN}$ is usually caused by abnormalities in the mitotic spindle, kinetocor or mitotic apparatus and chromosomal damage $[37,38]$. The fact that $\mathrm{MN}$ induction in meristematic cells indicates that 1,4-dioxane causes mitotic abnormalities and has genotoxic effect. Similarly, Teker et al. [1] reported 
that 1,4-dioxane treatment caused an increase in $\mathrm{MN}$ frequency in root tip cells in a dose dependent manner and they achieved a MN level of $46.70 \pm 11.91$ in the group treated with 100 ppm 1,4-dioxane. In this study, the protective properties of t-resv proven in previous parameters were also observed in $\mathrm{MN}$ and $\mathrm{Ml}$ analysis. T-resv application with 1,4-dioxane was found to cause improvement in MN and MI rates. This protective property of t-resv can be explained by its reducing effect against oxidative damage induced by 1,4-dioxane. In the previous analysis of this study, t-resv was found to reduce the rate of increased MDA and regulate the GSH level, thereby reducing oxidative damage. These results are the evidence that t-resv administration is protective against oxidative stress and same amerolative effect was also observed in MN and MI results. Similarly, Ranjini and Manonmani [39] reported that $100 \mu \mathrm{M}$ resveratrol treatment has protective effects against induced toxicity and has a reducing effect on MN formation and an an enhancing effect on cell viability.

The application of 1,4-dioxane has been found to cause changes such as flattened cell nuclei, cell wall thickening and cell deformation in the anatomical structure of A.cepa root. Root tissue can develop various adaptation mechanisms against toxic agents. Thickening of the cortex cell wall is one of the adaptation mechanisms, thereby reducing the access of the toxic agent to the internal tissues and the central cylinder $[40,41]$. In addition to the general structure of the cell, anatomical changes were observed in the cell nucleus. Flattening of the cell nucleus was observed with 1,4-dioxane application and this was associated with the cumulative effect of genotoxic and biochemical changes caused by 1,4-dioxane. A possible change in intracellular pressure and cell skeleton as a result of toxicity that disrupts the overall integrity of the cell may lead to shape changes of the organelles. The cell nucleus is generally spherical or ellipsoidal, but may change its shape in response to intracellular changes. Alterations in nuclear volume and protein concentration, degradation in DNA integrity and density may result in nuclear shape changes [42,43]. 1,4-dioxane induced peroxidation in membrane component lipids, disruption of DNA integrity by $\mathrm{MN}$ and CAs formations are the possible explanation for nuclear shape changes in Group IV. Although there is no study on the effect of 1,4-dioxane on anatomical damage, many studies have shown that many toxic agents cause changes and necrosis in epidermis and cortex cells [44,45]. With previous analyzes of this study it was found that 1,4-dioxane induced genotoxic effects and abnormalities in antioxidant system were found to be reduced by t-resv. Ameliorative effects of t-resv in other parameters have also been shown against anatomical damages. treatment with t-resv caused a significant decrease in anatomical changes especially in the frequency of flattened cell nucleus. Similar, Macar et al. [45] reported that $400 \mathrm{mg} / \mathrm{L}$ and $800 \mathrm{mg} / \mathrm{L}$ resveratrol application alleviate the anatomic damages in meristematic cells induced by $\mathrm{CuCl}_{2}$.

\section{Conclusion}

In this study, 1,4-dioxane, which has been used for various purposes in many sectors, has been shown to cause toxic effects on frequently dividing meristematic cells and it has been shown that t-resv has a amerolative effect against these toxicity. It has been determined that $100 \mathrm{mg} / \mathrm{L} \mathrm{1,4-dioxane} \mathrm{induces}$ genotoxic effects, causes a regression in germination and growth and serious changes in anatomical 
structure of meristematic cells. However, it has caused a change in antioxidant enzyme levels, a decrease in GSH level and an increase in MDA level, which is an indicator of lipid peroxidation. By altering the oxidant-antioxidant balance that is in equilibrium in living things, it decreased the cell's strength against oxidative damage. T-resv was found to have a amerolative effect against all these 1,4-dioxane-induced abnormalities and this effect was dose-dependent. $200 \mathrm{mg} / \mathrm{L} \mathrm{t}$-resv, one of the two tested doses, has a higher protective activity. However, it was also found that all the parameters tested were correlated and that the abnormalities observed in one parameter triggered other abnormalities. The decrease in $\mathrm{MI}$ rate naturally affect the root growth, weight gain and germination percentage. High concentrations of MN and CAs were observed in 1,4-dioxane-treated group, where abnormalities were observed in the antioxidant system. The improvement in antioxidant parameters with t-resv administration decreased the genotoxic effects. In short, all the data obtained in the study support each other and it is possible to elucidate the mechanism of toxicity with a multi-parameter study. Considering the amerolative effects of t-resv against genotoxic, physiological and biochemical toxicity, the importance of natural antioxidant foods emerges.Although there are many studies investigating the multiple biological properties of antioxidant plant foods, these studies are insufficient considering the high plant diversity. For this reason, studies on this subject will contribute to the literature and will guide other studies.

\section{Methods}

Test materials and grouping principles1,4-dioxane was purchased from Sigma-Aldrich and the other chemicals were supplied from Sigma-Aldrich. Allium cepa bulbs were used as target organism for determining the 1,4-dioxane toxicity. The identification of plant materials used in this study was applied by Dr. Zafer Türkmen from GRU Botanic Department. An example of plant material was deposited in a herbarium located in Botanical laboratory (GRU-FEF-23/2020). A. cepa bulbs were divided into six groups, one control and five application groups. Each group contained 6 bulbs and experimental stages given in Table 4. In each group bulbs were sterilized and germinated with related solution in individually controlled tubes at $24^{\circ} \mathrm{C}$ for 72 hours.

\section{Germination parameters}

The effects of 1,4-dioxane and t-resv on physiological parameters were investigaed by germination percentage, root length, weight gain and injury rate analysis. Germination percentage (GP) and Relative injury rate were calculated by using the Equation 1 and 2 [46]. Root length analysis was based on 10 root lengths and a mean value was calculated by random measurement from the ampoules of each group. For the weight gain analysis, the initial weight of each bulb and the weight at the end of the application were measured and the weight gain was determined using the difference between the first and last weight.

GP $(\%)=[$ Number of germinated bulb / Total number of bulb] $\times 100$

Relative injury rate $=[\% \mathrm{GP}$ in control $-\% \mathrm{GP}$ in each group $] /[\% \mathrm{GP}$ in control] 


\section{Cytogenetic parameters}

The effects of 1,4-dioxane and t-resv on MI, MN and CAs frequency and Ml levels were determined by using root tip preparations. After the germination period, healthy root tips from each ampoule were subjected to fixation procedures in serial ethanol solutions. After fixation, the root ends which were hydrolyzed with $1 \mathrm{~N} \mathrm{HCl}$ were stained with acetocarmine and crushing preparations were prepared. Entellan-fixed preparations were examined using a research microscope [47]. 1000 for MN and CA frequency analysis and 10000 for Ml analysis were counted. MI was claculated b using Equation 3 .

MI $(\%)=[$ Cell number in mitosis/ Total cell number $] \times 100$

\section{Antioxidant-oxidant balance}

The effects of 1,4-dioxane and t-resv on the antioxidant system were evaluated by examining MDA level and GSH, SOD and CAT levels, which are antioxidant parameters. Samples $(0.5 \mathrm{~g})$ from the meristematic tissues were homogenized in sodium phosphate buffer before all analyzes. GSH levels in homogenates were measured by acid soluble sulfhydryl level determination as described by Vecchia et al. [48]. The level of MDA, an indicator of oxidative stress was measured by a protocole reported by Unyayar et al. [49]. SOD activity was determined according to the procedure developed by Beauchamp and Fridovich [50] and expressed as U / mg FW. CAT activity was calculated according to the method proposed by Beers and Sizer [51] and the activity was expressed as OD240 $\mathrm{nm} / \mathrm{min}$.

\section{Anatomical changes}

All anatomical changes were examined by taking cross-sections from root tip. Cross-sections taken from the root tip of each group were stained with methylene blue by routine staining procedure and the preparations were fixed with entallen. The anatomical structures of each group were examined and a total of 1000 cells were examined for the frequency of anatomical changes [52].

\section{Statistical analysis}

Statistical analyzes were performed using the "IBM SPSS Statistics 22 SP" package program. Data were shown as mean $\pm S D$ (standard deviation). The statistical significance between the means was determined by One-way ANOVA and Duncan's test and $p$ value $<0.05$ was considered statistically significant.

\section{Abbreviations}

CAs Chromosomal abnormalities

CAT Catalase

GP Germination Percentage 


$\begin{array}{ll}\text { GSH } & \text { Glutathion } \\ \text { MN } & \text { Micronucleus } \\ \text { MI } & \text { Mitotic index } \\ \text { MDA } & \text { Malondialdehyde } \\ \text { SOD } & \text { Superoxide dismutase } \\ \text { T-RESV } & \text { Trans-resveratrol }\end{array}$

\section{Declaration}

Ethics approval and consent to participate

Not applicable.

\section{Consent for publication}

Not applicable.

\section{Availability of data and material}

Not applicable

\section{Competing interests}

The authors declare that there are no competing interests.

\section{Funding}

No funding

\section{Authors' contributions}

Initiated and designed the research: EY, KÇ

Performed the experiments: DK, EY, KÇ

Analyzed the data: DK, EY, KÇ

Wrote the paper: EY, KÇ

Edited and approved the final manuscript version: DK, EY, KÇ

The author(s) read and approved the final manuscript

\section{Acknowledgements}




\section{References}

1. Teker $D$, Çavuşoğlu K. Determination of cytotoxicity induced by 1,4 dioxane in root tip cells of Allium cepa L. (Amaryllidaceae). Iğdır Uni Nat App Sci J. 2013;3:31-

2. Environmental Protection Agency-EPA. Treatment technologies for 1,4-Dioxane. Fundamentals and Field Applications. EPA 542-R-06-009.2006.

3. Hawley GG, Lewis RJS. Hawley's Condensed Chemical Dictionary, New York, NY: John Wiley \& Sons, Inc. 2001.

4. Roy SK, Thilagar AK, Eastmond DA. Chromosome breakage is primarily responsible for the micronuclei induced by 1,4-dioxane in the bone marrow and liver of young CD-1 mice. Mutat Res. 2005;586:28-37.

5. Morita T, Hayashi M. 1,4-Dioxane is not mutagenic in five in vitro assays and mouse peripheral blood micronucleus assay but is in mouse liver micronucleus assay. Environ Mol Mutagen. 1998;32:269280.

6. Bhat KP, Kosmeder JW, Pezzuto JM. Biological effects of resveratrol. Antioxid Redox Signal. 2001;3:1041-

7. Fremont L. Biological effects of resveratrol. Life Sci. 200;66:663-

8. Martinez J, Moreno JJ. Effect of resveratrol, a natural polyphenolic com-pound, on reactive oxygen species and prostaglandin production. Biochem Pharmacol. 2000;59:865-870

9. Kampa M, Hatzoglou A, Notas G, Damianaki A, Bakogeorgou E, Gemetzi C, Kouroumalis E, Martin PM, Castanas E. Wine antioxidant polyphenols inhibitthe proliferation of human prostate cancer cell lines. Nutr Cancer. 2000;37:223-233.

10. Sun AY, Chen YM, Kracke MJ, Wixom P, Chen Y. Ethanol induced cell death by lipid peroxidation in PC12 cells Neurochem Res. 1997;22:1187-

11. Chanbitayapongs S, Draczynska LB, Sun AY. Amelioration of oxidative stress by antioxidant and resveratrol in PC12 cells. Neuro Report. 1997;8:1499-

12. Ray PS, Maulik G, Cordis GA, Bertelli AA, Bertelli A, Das DK. The red wine antioxidant resveratrol protects the isolated rat heart from ischemia reperfusion injury. Free Radic Biol Med. 1999;27:160169.

13. Jewett D, Lawless JG. Formate esters of 1,2-ethanediol. Major decomposition products of p-dioxane during storage. Bull Environ Contam Toxicol. 1980;25:118-121.

14. Burmistrov SO, Arutyunyan AV, Stepanov MG, Oparina TI, Prokopenko VM. Effect of chronic inhalation of toluene and dioxane on activity of free radical processes in rat ovaries and brain. Bull Exp Biol Med. 2001;132:832-836.

15. Xu S, Li J, Zhang X, Wei H, Cui L. Effects of heat acclimation pretreatment on changes of membrane lipid peroxidation, antioxidant metabolites, and ultrastructure of chloroplasts in two cool-season 
turfgrass species under heat stress. Environ Exp Bot. 2006;56:274-

16. Sağır S, Çavuşoğlu K, Yapar K. Investigation of physiological and genotoxic effects of 1,4 dioxane on swiss albino mice. Erzincan Uni Nat App Sci J. 2013;6:145-

17. Ayala A, Muñoz MF, Argüelles S. Lipid peroxidation: production, metabolism, and signaling mechanisms of malondialdehyde and 4-hydroxy-2-nonenal. Oxi Med Cell Longev.2014;31.

18. Esterbauer H, Schaur RJ, Zollner H. Chemistry and biochemistry of 4-hydroxynonenal, malonaldehyde and related aldehydes. Free Radic Biol Med. 1991;11:81-128.

19. Çöteli E, Alataş M, Batan N, Hazer Y. Comparing of glutathione levels of some Bryaceae (Bryophyta) species. Anatolian Bryology. 2019;5:15-21.

20. Leonard SS, Xia C, Jiang BH, Stinefelt B, Klandorf H, Harris GK, Shi X. Resveratrol scavenges reactive oxygen species and effects radical-induced cellular responses. Biochem Biophys Res Commun. 2003;309:1017-1026.

21. Al-Hussaini H, Kilarkaje N. Trans-resveratrol mitigates type 1 diabetes-induced oxidative DNA damage and accumulation of advanced glycation end products in glomeruli and tubules of rat kidneys. Toxicol Appl Pharmacol. 2018;339:97-109.

22. Mikstacka R, Rimando AM, Ignatowicz E. Antioxidant effect of trans-resveratrol, pterostilbene, quercetin and their combinations in human erythrocytes in vitro. Plant Food Hum Nutr. 2010;65:57-

23. Gupta YK, Briyal S, Chaudhary G. Protective effect of trans-resveratrol against kainic acid-induced seizures and oxidative stress in rats. Pharmacol Biochem Behav. 2002;71:245-

24. Fridovich I. Superoxide radical and superoxide dismutases. Annu Rev Biochem. 1995;64:97-

25. Özen $\mathrm{E}$. The protective effect of the green tea by some biochemical parameters on the rats injected 1,4-dioxane. University of Giresun, Graduate School of Natural and Applied Sciences, Deparment of Biology, Master Thesis. 2012;45-50.

26. Malar S, Vikram SS, Favas PJ, Perumal V. Lead heavy metal toxicity induced changes on growth and antioxidative enzymes level in water hyacinths. Bot Stud. 2016;55:

27. Maćczak A, Cyrkler M, Bukowska B, Michałowicz J. Bisphenol A, bisphenol S, bisphenol F and bisphenol AF induce different oxidative stress and damage in human red blood cells (in vitro study). Toxicol In Vitro. 2017;41:143-

28. Sadi G, Konat D. Resveratrol regulates oxidative biomarkers and antioxidant enzymes in the brain of streptozotocin-induced diabetic rats. Pharm Biol. 2016;54:1156-

29. Pintea A, Rugină D, Pop R, Bunea A, Socaciu C, Diehl HA. Antioxidant effect of trans-resveratrol in cultured human retinal pigment epithelial cells. J Ocul Pharmacol Ther. 2011;27:315-

30. Atmaca E, Aksoy A. Oxidative DNA damage and its chromatographic determination. J YYU Vet Med. 2009;20:79-83.

31. Levine RL, Yang IY, Hossain M, Pandya GA, Grollman AP, Moriya M. Mutagenesis induced by a single 1,N6-ethenodeoxyadenosine adduct in human cells. Cancer Res. 2000;60:4098-4104. 
32. Poon SL, McPherson JR, Tan P, Teh BT, Rozen SG. Mutation signatures of carcinogen exposure: genome-wide detection and new opportunities for cancer prevention. Genome Med. 2014;6:24.

33. Halliwell B. Effect of diet on cancer development: is oxidative DNA damage a biomarker? Free Radic Biol Med. 2002;32:968-

34. Ungvari Z, Orosz Z, Rivera A, Labinskyy N, Xiangmin Z, Olson S, Podlutsky A, Csiszar A. Resveratrol increases vascular oxidative stress resistance. Am J Physiol Heart C. 2007;292:2417-

35. Jang M, Pezzuto JM. Effects of resveratrol on 12-0-tetradecanoylphorbol-13-acetate-induced oxidative events and gene expression in mouse skin. Cancer Lett. 1998;134:81-89.

36. Russo T, Zambrano N, Esposito F, Ammendola R, Cimino F, Fiscella M, Jackman J, O'Connor PM, Anderson CW, Appella E. A p53-independent pathway for activation of WAF1/CIP1 expression following oxidative stress. J Biol Chem. 1995;270:29386-29391

37. Yalçın E, Uzun A, Çavuşoğlu K. In vivo epiclorohidrine toxicity: cytogenetic, biochemical, physiological, and anatomical evidences. Environ Sci Pollut Res. 2019;26:22400-22406.

38. Fenech M. Mechanisms by which genotoxins cause micronuclei and other nuclear anomalies. In The Micronucleus Assay in Toxicology. 2019;2-

39. Ranjini A, Manonmani HK. Resveratrol protects acrylamide/glycidamide induced genotoxicity in hepatic cell line. Pharm Innov J. 2019;8(1):56-64

40. Shu X, Yin L, Zhang Q, Wang W. Effect of Pb toxicity on leaf growth, antioxidant enzyme activities, and photosynthesis in cuttings and seedlings of Jatropha curcas L. Environ Sci Pollut Res Int. 2012;19:893-

41. Singh D, Pal M, Singh R, Singh CK, Chaturvedi AK. Physiological and biochemical characteristics of Vigna species for Al stress tolerance. Acta Physiol Plant. 2015;37:1-13

42. Dahl KN, Ribeiro AJ, Lammerding J. Nuclear shape, mechanics, and mechanotransduction. Circ Res. 2008;102:1307-

43. Dauer WT, Worman HJ. The nuclear envelope as a signaling node in development and disease. Dev Cell. 2009;17:626-

44. Çavusoglu K, Yalçın E. Antioxidant-oxidant balance and vital parameter alterations in an eukaryotic system induced by aflotoxin B2 exposure. Environ Sci Pollut Res. 2019;26:37275-37281.

45. Macar TK, Macar O, Yalçın E, Çavuşoğlu K. Resveratrol ameliorates the physiological, biochemical, cytogenetic, and anatomical toxicities induced by copper (II) chloride exposure in Allium cepa L. Environ Sci Pollut Res. 2019;1:11.

46. Praveen A, Gupta M. Nitric oxide confronts arsenic stimulated oxidative stress and root architecture through distinct gene expression of auxin transporters,nutrient related genes and modulates biochemical responses in Oryza sativa Environ Poll. 2018;240:950-962.

47. Çavuşoğlu K, Doğu F, Çavuşoğlu D. Effects of sodium hypochlorite on some physiological and cytogenetical parameters in Allium cepa Exposed to salt stress. Bangladesh J Bot. 2019;48:223-229. 
48. Vecchia C, Negri E, Franceschi S, D'Avanzo B, Boyle P. Tea consumption and cancer risk. Nutr Cancer. 1992;17:27-31.

49. Unyayar S, Celik A, Cekic FO, Gozel A. Cadmium-induced genotoxicity, cytotoxicity and lipid peroxidation in Allium sativum and Vicia faba. Mutagenesis. 2006;21:77-

50. Beauchamp C, Fridovich I. Superoxide dismutase: improved assays and an assay applicable to acrylamide gels. Analytic Biochem. 1971;44:276-

51. Beers RF, Sizer IW. A spectrophotometric method for measuring the breakdown of hydrogen peroxide by catalase. J Biol Chem. 1952;195:133-140.

52. Akgündüz MÇ, Çavuşoğlu K, Yalçın E. The potential risk assessment of phenoxyethanol with a versatile model system. Sci Rep. 2020;10:1209.

\section{Tables}

Table 1 The effects of 1,4-dioxane and the amerolative effects of t-resv on germination parameters

\begin{tabular}{|c|c|c|c|c|c|}
\hline Groups & $\begin{array}{l}\text { GP } \\
(\%)\end{array}$ & $\begin{array}{c}\text { Relative Injury } \\
\text { Rate }\end{array}$ & $\begin{array}{c}\text { Root } \\
\text { lenght } \\
(\mathrm{cm})\end{array}$ & $\begin{array}{c}\text { Final } \\
\text { weight } \\
\text { (g) }\end{array}$ & $\begin{array}{c}\text { Weight } \\
\text { Gain } \\
\text { (g) }\end{array}$ \\
\hline Group I & 100 & 0.00 & $9.50 \pm 1.64^{\mathrm{a}}$ & $11.00 \pm 1.43^{\mathrm{a}}$ & $6.00^{\mathrm{a}}$ \\
\hline Group II & 100 & 0.00 & $9.63 \pm 1.47^{\mathrm{a}}$ & $11.13 \pm 1.63^{\mathrm{a}}$ & $6.14^{\mathrm{a}}$ \\
\hline Group III & 100 & 0.00 & $9.70 \pm 1.68^{\mathrm{a}}$ & $11.36 \pm 1.61^{\mathrm{a}}$ & $6.32^{\mathrm{a}}$ \\
\hline Group IV & 60 & 0.40 & $0.75 \pm 0.31^{d}$ & $5.83 \pm 0.42^{\mathrm{d}}$ & $0.78^{d}$ \\
\hline Group V & 70 & 0.30 & $2.00 \pm 0.63^{\mathrm{c}}$ & $6.57 \pm 0.51^{b}$ & $1.50^{\mathrm{c}}$ \\
\hline Group VI & 84 & 0.16 & $4.50 \pm 0.80^{b}$ & $8.47 \pm 0.88^{c}$ & $3.45^{\mathrm{b}}$ \\
\hline
\end{tabular}

Group I: Tap water, Group II: 100 mg/L t-resv, Group III: 200 mg/L t-resv, Group IV: 100 mg/L 1,4-dioxane, Group V: 100 mg/L 1,4-dioxane+100 mg/L t-resv, Group VI:100 mg/L 1,4-dioxane+200 mg/L t-resv. Different letters in the same column indicate statistical significance.

Table 2 The effects of 1,4-dioxane and t-resv treatment on CAs frequency

\begin{tabular}{|c|c|c|c|c|c|}
\hline Groups & FRG & SC & UDC & B & VC \\
\hline Group I & $0.00 \pm 0.00^{\mathrm{d}}$ & $0.00 \pm 0.00^{\mathrm{d}}$ & $0.30 \pm 0.48^{\mathrm{d}}$ & $0.00 \pm 0.00^{\mathrm{d}}$ & $0.30 \pm 0.48^{\mathrm{d}}$ \\
\hline Group II & $0.00 \pm 0.00^{\mathrm{d}}$ & $0.00 \pm 0.00^{d}$ & $0.30 \pm 0.48^{\mathrm{d}}$ & $0.00 \pm 0.00^{\mathrm{d}}$ & $0.10 \pm 0.32^{\mathrm{d}}$ \\
\hline Group III & $0.00 \pm 0.00^{d}$ & $0.00 \pm 0.00^{d}$ & $0.20 \pm 0.42^{\mathrm{d}}$ & $0.00 \pm 0.00^{d}$ & $0.00 \pm 0.00^{\mathrm{d}}$ \\
\hline Group IV & $60.00 \pm 8.86^{\mathrm{a}}$ & $42.00 \pm 8.00^{\mathrm{a}}$ & $35.00 \pm 8.69^{a}$ & $30.00 \pm 5.91^{\mathrm{a}}$ & $22.00 \pm 6.02^{\mathrm{a}}$ \\
\hline Group V & $48.00 \pm 8.10^{b}$ & $34.00 \pm 7.00^{\mathrm{b}}$ & $28.00 \pm 5.16^{b}$ & $23.00 \pm 5.66^{b}$ & $16.00 \pm 5.10^{\mathrm{b}}$ \\
\hline Group VI & $36.00 \pm 9.14^{\mathrm{c}}$ & $25.00 \pm 5.73^{c}$ & $20.00 \pm 5.77^{\mathrm{c}}$ & $15.00 \pm 5.54^{c}$ & $10.00 \pm 3.50^{\circ}$ \\
\hline
\end{tabular}

Group I: Tap water, Group II: 100 mg/L t-resv, Group III: 200 mg/L t-resv , Group IV: 100 mg/L 1,4-dioxane, Group V: 100 mg/L 1,4dioxane+100 mg/L t-resv, Group VI:100 mg/L 1,4-dioxane+200 mg/L t-resv . Different letters in the same column indicate statistical significance. FRG:fragment, SC:sticky chromosome, UDC:unequal distribution of chromatine, B:bridge, VC:vagrant chromosome 
Table 3 Frequency of anatomical changes in all experimental groups

\begin{tabular}{lllllll}
\hline & Group I & Group II & Group III & Group IV & Group V & Group VI \\
\hline Thickening in cell wall of cortex & - & - & - & +++ & +++ & ++ \\
\hline Flattened cell nucleus & - & - & - & +++ & ++ & + \\
\hline Epidermis cell deformation & - & - & - & ++++ & +++ & ++ \\
\hline (-): No change, $(+)$ : mild change, $(++)$ : moderate change, $(+++)$ : severe change, $(++++)$ : serious change \\
\hline
\end{tabular}

Table 4 Experimental groups

\begin{tabular}{ll}
\hline \multicolumn{1}{c}{ Group } & Treatment \\
\hline Group I & Tap water \\
Group II & $100 \mathrm{mg} / \mathrm{L}$ t-resv \\
Group III & $200 \mathrm{mg} / \mathrm{L}$ t-resv \\
Group IV & $100 \mathrm{mg} / \mathrm{L} \mathrm{1,4-dioxane}$ \\
Group V & $100 \mathrm{mg} / \mathrm{L} 1,4$-dioxane $+100 \mathrm{mg} / \mathrm{L} \mathrm{t}$-resv \\
\end{tabular}

\section{Figures}



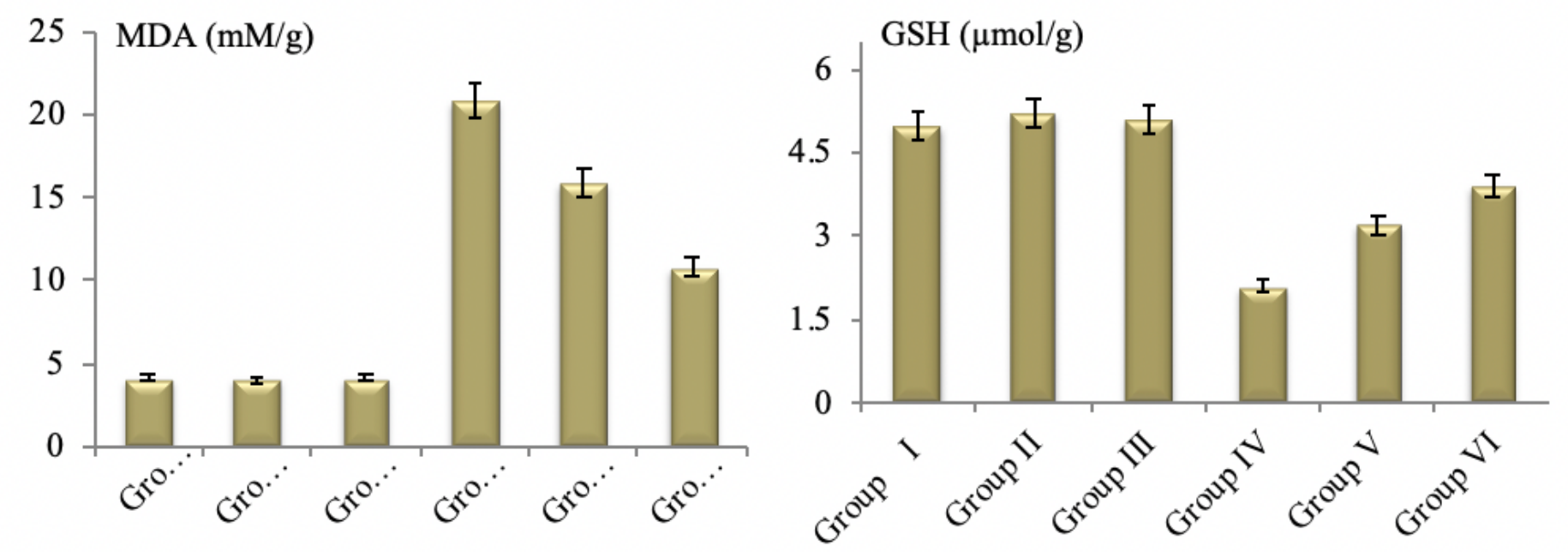

Figure 1

The effects of 1,4-dioxane and t-resv treatment on MDA and GSH levels
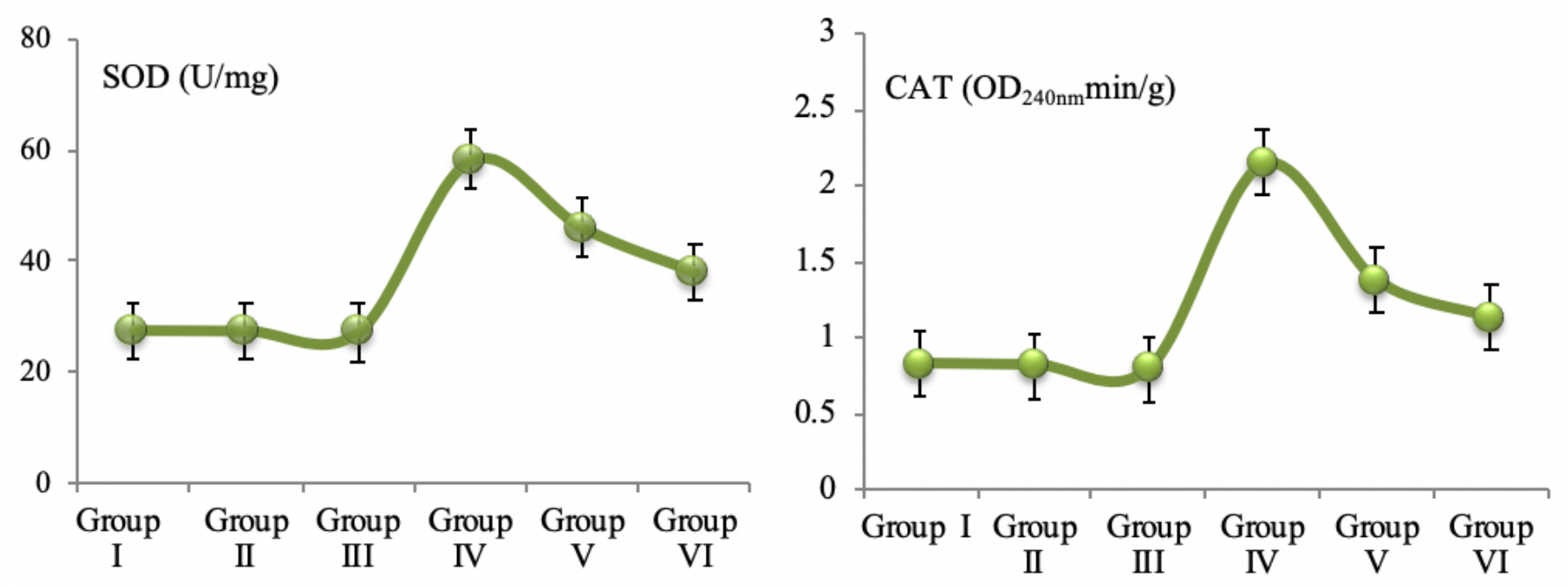

Figure 2

The effects of 1,4-dioxane and t-resv treatment on SOD and CAT activities 


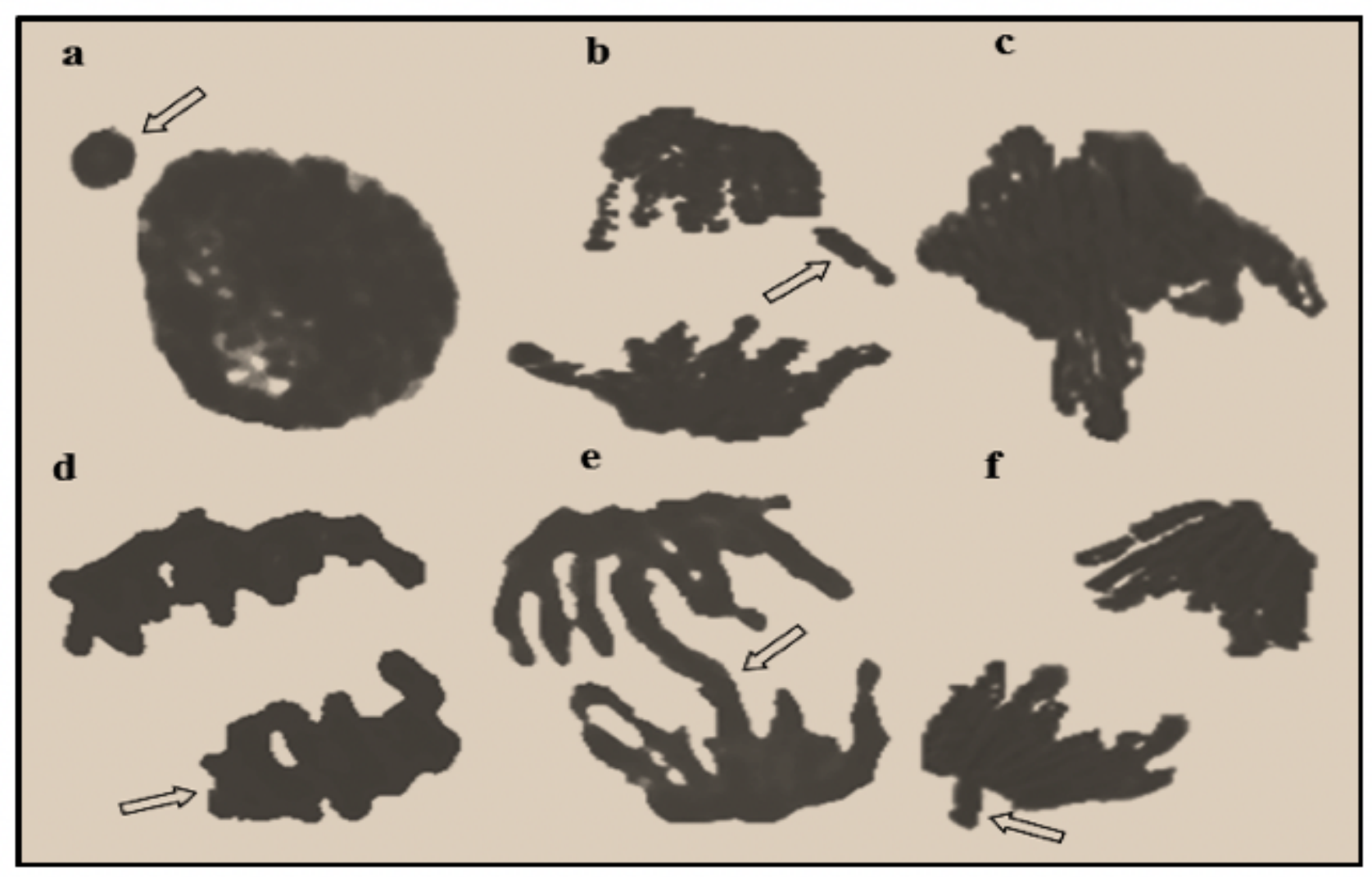

Figure 3

CAs and MN formations induced by 1,4-dioxane a MN. b fragment. c sticky chromosome. $d$ unequal distribution of chromatine. e bridge. f vagrant chromosome
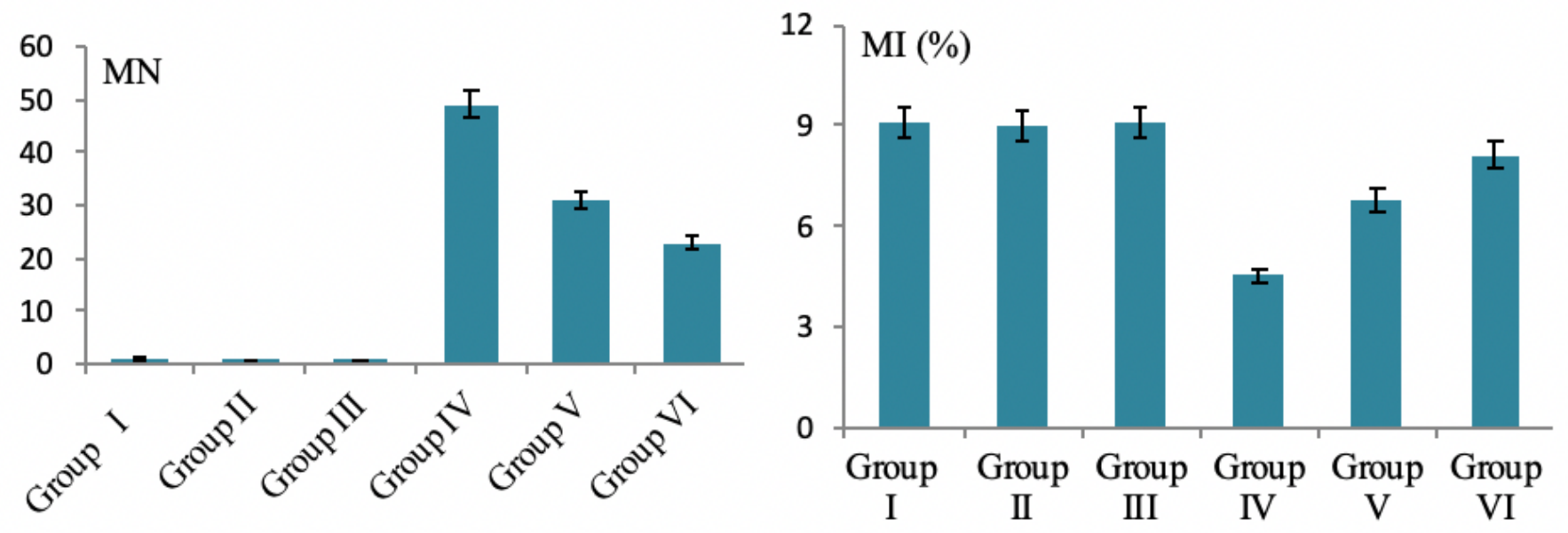

Figure 4

The effects of 1,4-dioxane and t-resv treatment on MN frequency and $\mathrm{MI}$ 

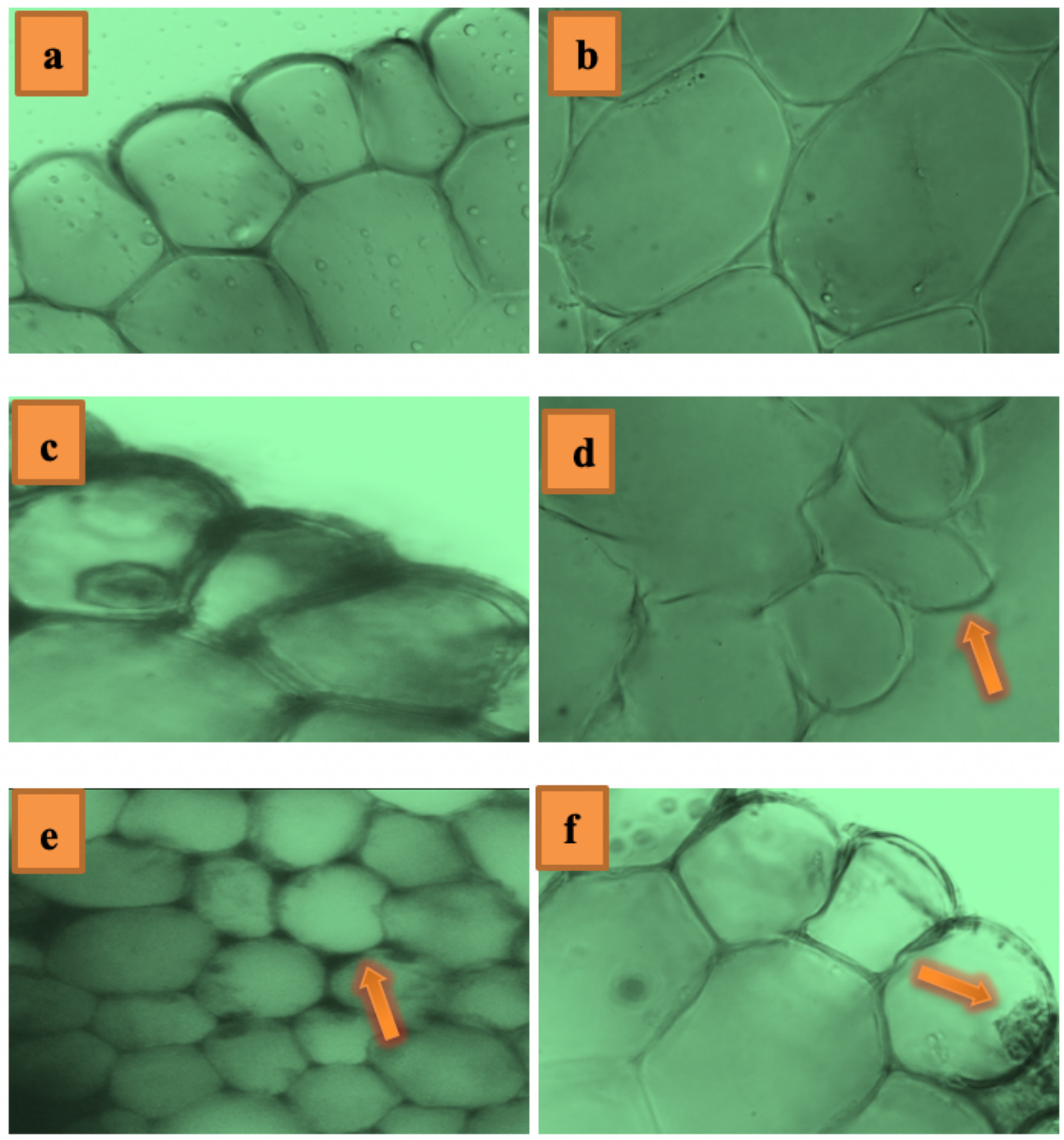

Figure 5

Anatomical changes in A. cepa meristematic cell induced by 1,4-dioxane a epidermis cells in control. b cortex cells in control. c normal view of cell nucleus. $d$ epiderrmis cell deformation in 1,4-dioxane treated group. e cortex cell wall thickening in 1,4-dioxane treated group. f flattened cell nucleus in 1,4-dioxane treated group 